"This is the peer reviewed version of the following article: Arreciado, A. \& Isla, M.P. (2016) Contradictory views of nursing care among students at the end of their nursing education. Journal of Advanced Nursing 00(0), 000-000, which has been published in final form at DOI: 10.1111/jan.13114. This article may be used for noncommercial purposes in accordance with Wiley Terms and Conditions for SelfArchiving."

\title{
Contradictory views of nursing care among students at the end of their nursing
}

\section{education}

Antonia Arreciado Marañón ${ }^{1} \&$ Ma Pilar Isla Pera ${ }^{2}$

${ }^{1} \mathrm{PhD}$. Professor of Nursing Department and Coordinator of the Master in Surgical Nursing. Nursing Department, Universitat Autònoma de Barcelona, Spain.

${ }^{2} \mathrm{PhD}$. Professor of Nursing Department and Coordinator of the Master in Principles of Care and Education For Diabetes Sufferers Public Health, Mental Health and Maternal Department, Universitat de Barcelona, Spain. 


\begin{abstract}
Aim. To understand how nursing students at the end of their nursing education view nursing care.
\end{abstract}

Background. Although care is understood as the essence of nursing, it is often difficult for nurses to provide care, which demonstrates a contradiction between theory and practice. Moreover, it is unknown to what extent this contradiction is transmitted to future nursing professionals or how they view nursing care and its practice.

Design. Qualitative ethnographic research.

Methods. The fieldwork was conducted between December 2010 and May 2012 in a university nursing school in Barcelona and two centres where students carry out most of their practical education. The data collection techniques were participant observation and focus groups. A thematic analysis was used.

Results. The students demonstrated contradictory views of nursing care. On one hand, they voiced a more theoretical, official definition in which care is considered the core of the profession. On the other hand, they also expressed a view in which the provision of care is not nurses' principal daily activity, a fact that did not surprise them. Students interpreted caring as an activity that has low value and that can be transferred unproblematically to other professionals.

Conclusion. The contradictory views of care reveal a problem in the transmission of the definition of nursing to new generations of professionals and reflect a problematic professional reality in which there is dissonance between how nursing is defined and how it is carried out in practice. 


\section{SUMMARY STATEMENT}

\section{Why is this research or review needed?}

- Although care is defined as the core of nursing, in practice nurses often spend most of their time on other tasks. It is unknown how future professionals view this contradiction.

- Examining the views of the next generation of nurses can help scholars comprehend the current reality of nursing and predict future directions of the profession.

- Taking the point of view of the protagonists offers a unique qualitative perspective that can help professionals redirect both the teaching and the practice of nursing.

\section{What are the key findings?}

- Students have contradictory views of nursing. The findings reveal a problem in the transmission of the definition of nursing to new generations of professionals.

- Students claim that care is the core of the profession but, they also report (without concern) that nurses lack time to provide care and that they delegate care to others.

- Care is a little-valued activity whose undervaluation or delegation to other professionals does not seem problematic to these students who soon will become the next generation of nurses.

\section{How should the findings be used to influence policy/practice/research/education?}

- Given that care defines the profession, nursing education and clinical nursing practice should be reoriented to reflect the core value attributed to care.

- The findings should be the basis for developing strategies that can contribute to preventing the vicious cycle that reproduces specific roles and attitudes surrounding care. 
- Strategies include the development of new curricula as well as the implementation of workspaces allowing collaboration among academics, practicing nurses, policymakers and administrators.

Key words: Care; Caring; Delegation; Nurses; Nursing; Nursing education research; Qualitative research; Students, Nursing.

\section{INTRODUCTION}

Despite an active scholarly tradition in nursing, there is no single definition of nursing (Henderson 2006) or the professional roles of nurses (Currie \& Carr-Hill 2013). Nonetheless, there seems to be broad consensus on the idea that care is the essence of nursing (Kozier 2005, Khademian \& Vizeshfar 2008, Begum \& Slavin 2012, Sargent 2012, Labrague et al. 2015). In spite of this agreement in established discourse, which situates care at the core of the profession, it remains difficult for nurses to provide care in clinical settings. This fact reflects a contradiction between what is said and what is done (Alberdi 1992).

At the same time, it is unclear to what extent this contradiction is transmitted to future professionals or how they view nursing care and its practice. The university is an ideal site to investigate this question because here new nurses acquire skills that will enable them to practice the profession (Barrenetxea et al. 2013) and also ideas about what nursing is. It is also a place for the interplay of ideas about the profession that emerge from society and from the institution itself. During their formal education, students acquire the knowledge, skills, attitudes and values associated with their professional role (Wade 1999, Dimitriadou et al. 2013). The socialisation process that they undergo changes certain beliefs, images, attitudes and values that the student brings with him or her (Shinyashiki et al. 2006). It is important, therefore, to know how nursing students conceive of the profession at the end of their training 
and, in particular, their views of care. Qualitative research makes it possible to understand the phenomenon in depth, by considering the point of view of the students as protagonists.

\section{Background}

The concern over how best to define nursing is not new. In 1977, Virginia Henderson noted the discrepancy between, on the one hand, nurses' own image of their work and, on the other hand, their public image. She claimed that instead of a universal concept of nursing, different definitions co-existed in the minds of the general public and of nurses themselves (Henderson 2006). Nonetheless, for the author, nursing had an exclusive function that only the nurse could carry out (Henderson \& ICN 1971): care. She noted, however, that its implementation in practice was not uniform.

Other scholars have also described nursing as a profession whose primary function is the provision of care (Kozier 2005, Marriner \& Alligood 2007). According to the International Council of Nurses (2002), "Nursing encompasses autonomous and collaborative care of individuals of all ages, families, groups and communities, sick or well and in all settings". That is, there is a consensus on a theoretical level that establishes care as the essence and main function of nursing (Morse et al. 1990, Alberdi 1992, Khademian \& Vizeshfar 2008, Begum \& Slavin 2012, Sargent 2012, Labrague et al. 2015).

\section{Care and its implementation}

As we have seen, it is widely accepted that providing care is the objective of nursing and the feature that distinguishes it from other professions. According to some authors, this is because for years nursing theory has claimed care as the central axis of nursing practice (Sargent 2012). Nonetheless, its definition remains complex and ambiguous (Khademian \& Vizeshfar 2008, Sargent 2012). Alberdi (1992) has shown that in spite of the focus on care in definitions 
of nursing, providing care continues to be difficult in practice because of an overload of tasks related to procedures, diagnosis or equipment (Lleixá et al. 2009). Nurses' daily obligations often minimize the opportunity to provide care, even though care is what gives meaning to the profession (Sánchez 2002). In some instances, a healthcare setting oriented primarily toward illness draws nurses away from their true mission (Palacios 2007). Two consequences are the delegation of care and the prioritization of tasks carried out in collaboration with doctors (García \& Buendía 2001, Cano-Caballero 2004, Alberdi \& Cuxart 2005). Beginning students from nursing and other fields share the view that nursing care focuses on clinical and technical assistance (Gómez et al. 2008). In fact, some studies show that nursing students themselves attribute greater importance to technical forms of care rather than those related to relationships or comfort (Khademian \& Vizeshfar 2008).

These statements are not new. In 1991 Collière revealed that nurses' work was only recognised when it depended on helping the doctor. "Everything that doesn't contribute to giving exams and administering and overseeing treatments is nothing more than an approximation... work that is invisible, unknown, unrecognized" (Collière 1991, p.61). Nurses' care activities are often not recognized, which makes them invisible to others. Thus, providing company, solace or comfort to a patient is not considered relevant, and this judgment often results in these activities being omitted from records (Celma \& Acuña 2009). This low value attributed to care, caused among other factors by its historical tie to women's activities (Fajardo \& Germán 2004), challenges the essence of the profession. It confers greater value on technological or other aspects than on the provision of care (Domínguez 1989). On other occasions, care is transferred out of professional hands and into the hands of family members and assistants. If care is considered to be the core of the discipline, the fact that it can be transferred so easily is a major concern (De la Cuesta 2007). 
Despite these conflicts surrounding the definition and implementation of care, little attention has been paid to understanding how care is viewed by graduating nursing students. Understanding their view of this key aspect of the profession is necessary because these students will soon replace the current generation of nurses.

\section{THE STUDY}

\section{Aim}

The aim of this study was to understand how nursing students at the end of their nursing education view nursing care.

\section{Design}

A qualitative, ethnographic study was conducted. Ethnography is selected as the most appropriate methodological strategy to approach the study aim: to understand nursing students' view of care. Their experience as students contributes to the creation of this view, as they become immersed in professional nursing culture. Ethnography made it possible to gain access to the beliefs and practices of members of the profession that the students hope to join and obtain data in their natural context. A basic idea of ethnographic theory is that a group's culture - in this case, its beliefs and values surrounding care-is learned and shared by its members (Morse 2005). For this reason, it was necessary to gain access to this group, in which the students are immersed during their education. Moreover, ethnography offered the opportunity to understand the viewpoint of the protagonists from their perspective (emic), while also coming to understand these meanings from the outside (etic). 


\section{Participants}

The fieldwork was conducted in three sites. These were a university nursing school in Barcelona (UNS) and two centres where UNS students carry out most of their practical education: a public hospital and a primary care centre.

The study population was composed of 87 third-year nursing students in the Diploma program, 80 of whom were women and seven of whom were men. To be included, students had to meet the following requirements: be third-year nursing students at the UNS; have begun and continued their studies solely at the UNS; and participate voluntarily in the study. The sample was purposive and aimed to include participants with certain characteristics that would guarantee the quality and quantity of information (Valles 2007). The characteristics of participants are described in the findings section. Identification of possible participants was made with the help of a third-year student. She received instructions on the characteristics the participants should have. In this manner, from among the 87 third-year nursing students a list of approximately 40 possible participants was generated, a sufficient number to allow for the probability that some would decline to participate, that there could be later cessations and that data saturation had to be reached. Later, also with the help of the same third-year student, personal contact with each participant was made and interviews began. In the end, data saturation was reached by interviewing 23 participants of the 40 possible participants identified.

\section{Data collection}

The fieldwork was conducted between December 2010 and May 2012. The data collection techniques were participant observation and focus groups. Observation periods made it possible to access the professional reality in which nursing students are immersed during their education. Students were observed in everyday contexts (Taylor \& Bogdan 1992) in order to 
share in their realities and understand them better. To accomplish this goal, the main researcher observed the relationship that they established with nurses and the context in which these relationships evolved. Research began with general observations about what participants said and did and later become focused more specifically on the study objectives. The observations were conceived as an initial step that could reveal priorities in nursing culture and provide a source of questions for the focus groups (Schensul et al. 1999). The fieldwork took place at the hospital and at the primary care centre and it lasted for the entire period in which the students were in these sites, a total of four months. The first author conducted all observations and focus groups. With the help of key informants, departments were chosen based on their ability and willingness to provide access to the students and the nurses who trained them. These departments were also chosen because they hosted large numbers of students undertaking their practical education, which made it possible to observe multiple students in a wide variety of activities and situations. An open strategy (Berenguera et al. 2014) was used to share information about the study, but specific study goals were not discussed in order to prevent influencing the results. Because the field sites had frequent visitors and because the first author spent a prolonged period there, it was possible to avoid standing out and to minimise the effect on the actions or behaviours of others (Ruiz 2007). Throughout the fieldwork process, detailed field notes were taken, first on site in a notepad and later in a digital field diary written as soon as possible after each observation period.

Student focus groups were prepared based on the information collected during observations (Krueger 1991). The first author carried out three focus groups of eight, eight and seven participants, respectively, until reaching data saturation (Valles 2007, Berenguera et al. 2014). Only one of the students that had been observed was available to form part of a focus group. The composition of the groups took into account the variables of gender, age, marital status, geographical origin and work experience in the healthcare world. These 
criteria, when combined with the fact that all of the students were third-year nursing students, guaranteed the necessary heterogeneity (diversity) and homogeneity (typicality) (Krueger 1991, Suárez 2005). Following Krueger (1991), the focus group schedule presented openended questions structured in a logical sequence. Some of them are shown in Table 1. Some aspects emerged spontaneously so it was not necessary to ask all questions listed in the guide. In other cases, additional questions were asked when necessary. All groups were audiorecorded and the moderator took notes. The length of the sessions was 105, 145 and 100 minutes, respectively. The recordings were then transcribed.

\section{Ethical considerations}

The project was approved by the Committee on Ethics and Animal and Human Experimentation of the university (CEAAH 2497) and permission was granted by the head of nursing at both healthcare sites. Participation was voluntary and participants gave written informed consent. Anonymity was guaranteed by assigning an alpha-numeric code to each participant. Fictitious names are used in the extracts in order to humanise the participants and female names were given to the three males to avoid identification. After data collection, participants had the opportunity to approve its contents, modifying it when necessary.

\section{Data analysis}

Keeping in mind that qualitative analysis cannot be separated from the process of data collection first, the observational data were analysed as a baseline for preparing the focus groups. Next, an initial analysis was performed on the focus group data. Finally, the observational and focus group data were combined for the remainder of the analytical process. A thematic analysis was used and was performed in the following phases: First of all, notes and transcripts were read in detail multiple times. From these initial readings an initial list of 
intuitions, ideas and interpretations was developed. Then, meaning units were identified, segmented and grouped into themed categories (Ruiz 2007). This categorisation process was open, and categories were constructed emergently (Berenguera et al. 2014). In addition, categories were mutually exclusive (De Andrés 2000). Namely, each meaning unit was included only in one category, even if it could have been relevant to more than one thematic area. After grouping these categories into larger categories and analysing them thoroughly, a final explanatory framework was developed. In this final phase, special attention was paid to ensure that the findings emerged from the original textual corpus. In order to organise and categorise the data, ATLAS/ti version 6.2 was used.

\section{Rigour}

To guarantee the rigour and credibility of data collection and analysis, Guba's (1981) criteria of credibility, transferability, dependability and confirmability were applied. With respect to credibility, a prolonged period of participant observation made it possible to acquire a deep understanding of the phenomenon under study. The triangulation of methods achieved through participant observation and focus groups made it possible to compare results across these two contexts and therefore ensure the dependability and consistency of the data. Moreover, the collected data were checked with the participants, who confirmed their accuracy, and both researchers participated in the data analysis.

As for transferability, strategies included collecting abundant descriptive data and making detailed descriptions of all factors related to the study, making it possible to apply the results to other similar contexts. Finally, confirmability was ensured via the triangulation of methods and by the researchers' on-going review of data and research processes. 


\section{FINDINGS}

Of the 24 students who agreed to participate in the focus groups, one belonging to the final group did not attend. Twenty of the 23 participants were women and three were men. Five were married or lived with a partner and the rest were single. Five had experience as nursing assistants. Their ages ranged from 20 to 54 years, although most (18 participants) were between 20 and 22 years old (Table 2). Findings draw on data both from participant observation and focus groups. Two key themes emerged: a) care as a defining aspect of nursing and $b$ ) the delegation of care.

\section{Care as a defining aspect of nursing}

In the students' attempt to define what a nurse is and what nurses do in their professional realm, they drew on "textbook" descriptions of key concepts.

What does being a nurse mean to you?:

"It's the need to acquire knowledge in order to be able to care for people both in sickness and in health, in order to give them autonomy. And the comfort of the patient, of the family, as a biopsychosocial being, at all levels. For me that's what caring is". (GD1, Estefanía, 18)

As can be seen, the care component emerged in the responses spontaneously in response to a question about what a nurse is. For these students, as can be seen in the following examples from the discussion groups, care is what defines the nursing profession and differentiates it from others. Moreover, care is understood as comprehensive help offered to others.

\footnotetext{
"Because we provide care. But it's about the professionalization of the fact of caring". (GD1, Aina, 52)
}

“To treat a person like a biopsychosocial being...”. (GD 3, Paula, 164) 
"For me nursing is a profession in which you really help people. In my case, I love helping people, and when it comes to illness, which is a critical moment for patients, being able to be there and help them...". (GD2, Pepi, 38)

The help students refer to is fundamentally psychological assistance, especially when a person is hospitalised. The biological or even social aspects of the profession are not as relevant to students.

“...That's a small part of what the nurse has to do for the patient: giving medication, putting in IVs, just a few things. But really, the important part is the rest, the emotional support that she can give to the patient, and I really didn't know". (GD3, Asun, 56)

The participants see care as an interactive and reciprocal process; helping others becomes a way of helping themselves.

“... Being able to help and to have that role of being able to help people take on challenges and overcome difficult situations. It's hard but it's part of what makes you feel good as a person, it makes you feel like you're doing something good". (GD 1, Cristina, 24)

The most suitable way to provide this help is through positive personal contact. For students, treating the patient well is an essential aspect of nursing and forms a part of care. This fact was confirmed on numerous occasions during the observation period. When the students entered patient rooms, regardless of the task at hand, they attempted to establish contact with the patients, asking how they were or initiating conversations to show their interest. This also occurred during procedures, as we see in the follow example taken from field notes: 
(who were alone) and the student explained to one patient that she was going to change his IV. While doing so, she asked whether he had eaten and whether his meal had agreed with him. Later, she asked the other patient the same. They responded pleasantly and made jokes about the food. The student was responsible for taking initiative in this encounter. The nurse observed and participated in the conversation. The conversation continued, with the student commenting on the magazine that one of the patients was reading for entertainment. The atmosphere was very relaxed. (OBS 7,25$)$

Students' treatment of the patient and the family indicates concern for and interest in them and their situation. This trait was also found in the focus groups:

"What sticks with me is the fact that nursing—being a nurse - is dealing with people and doing things for them, and in the most suitable way. The goal is the wellbeing of the person that needs it [nursing care]". (GD 2, Isabel, 408)

This personal contact is based on respect and humanity towards the person needing care. Sensitivity and solidarity toward the suffering of others appear as essential traits.

"For me, one thing that nursing has always instilled in me is love, peace, respect and esteem for the other person...”. (GD3, Montse, 286)

Moreover, in accordance with the above, students object when nurses fail to offer these aspects of care, as seen in the following examples:

"I tell my family that if at some point you see that I'm insensitive to what the patient says or to his pain, tell me, because I'll leave it [the nursing profession]. I can't stand it when a nurse is insensitive to what the person opposite them is saying”. (GD 2, Angels, 398)

"I can't stand a nurse's lack of humanity with a patient, treating him like an object, spending only just enough time with him to handle whatever task and that's it". (GD 2, Sandra, 396) 


\section{Delegation of care}

As shown in the previous section, students agree that care is the defining feature of nursing. However, students with prior experience as nursing assistants mention spontaneously that in practice nurses often delegate care to nursing assistants. They understand that nurses help people but note that constraining factors prevent them from dedicating more of their time to this task. Thus, students with prior experience depict the image of nursing-as-care as an idealised view held by beginners.

"I'm pleased because the experience of being a nursing assistant gave me a really different view of nursing. (...) The nurse attends to the patients to handle their pressing needs and she applies the necessary techniques. She has to fill out the chart or she has questions and she has to talk to the doctor and look for him and make sure the necessary change gets made. And these are situations that take time. And then, caring for the patient has a certain tone. Things like take me there, bring me that, I'm dirty, change me, etc. The assistant takes care of these things. So, the nursing assistant is the person that feeds the patients, gives them their pills and is going to spend more time with them...”. (GD 2, Neus, 72)

The students who have worked as nursing assistants talk about the transfer of care from nurses to assistants. Professional experience leads them to affirm that assistants are the people who spend the most time with patients and who cover their basic needs. Workloads and time constraints mean that nurses handle certain tasks and delegate tasks that they consider more basic to nursing assistants.

"The people who make sure the patient eats and who take care of his hygiene and comfort are the nursing assistants. The assistants are there for any of these things that the patient needs. Of course, they spend more time with patients than the nurse does”. (GD 3, Nerea, 224) 
Only the students with experience as nursing assistants mention the delegation of care spontaneously, without prompting. As seen above, students without a nursing assistant background stress care as the role of nurses; they do not spontaneously mention delegation, although they reluctantly acknowledge it when it has been previously mentioned by someone with experience as an assistant, as seen in the following example:

"It's true that nursing assistants take care of many of the basic needs, but that's what they're there for, to help and work with the nurse in order to meet all those needs. If the nurse had to do all of it, obviously she wouldn't have time. What you say [referring to Neus, the student with experience as a nursing assistant] about having to chase down the doctor so that he can tell you which medication or that you have to handle a ton of charts is true. It's true that it takes time, but it's also true that it's necessary for the patient”. (GD 2, Lourdes, 88)

It should also be noted that only one student associates care with nursing autonomy. According to this idea, the nurse is responsible for the independent management of basic care.

"For me, at the moment I think that being a nurse is having autonomy. There's another role, which is that of the doctor who is going to tell you what you have to do or to carry out with a certain patient, but when it comes to handling the basic needs, of having a bit of a say, it's nursing”. (GD 2, Neus, 34)

For the rest of participants, this area does not stand out in terms of the practice of professional autonomy. The provision of basic care is not central enough for most students to mention it when they talk about nursing autonomy. The undervaluing of care activities is a reality in which they find themselves immersed and which they do not question. This finding is paradoxical considering that the same students define care as the core of nursing.

The majority of students agree that caring has scant social recognition in the face of the hegemony of curing. But even the students themselves gave few examples in which they 
attributed high importance to caring activities linked, for example, to hygiene, diet, well-being or comfort. The following example is one of the few exceptions:

"Taking a blanket to an elderly woman who had been in the emergency waiting room for four hours (...) and seeing her start to cry because no one had noticed that she was cold, no one. (...). And it's not that it's anything technical, but emotionally you've made her more comfortable. Later, that will have an impact on her stay, she'll come to trust you, she'll let you help her with her illness, with her treatment.”. (GD 2, Gisela, 24)

These care activities seem to be accorded such little priority that they are not the subject of students' questions to nurses, as was revealed during the observation period. Questions deal mainly with medication, pathologies and its signs and symptoms. There are few occasions in which students and nurses discuss the needs of the patient or how to evaluate them or why a nurse has performed a certain act of care. The students do not appear to have a need to discuss these aspects, which is also revealing.

As we have seen, despite the fact that students consider care to be the core of the profession, in general they are not surprised that nurses spend most of their time on other activities and that they often delegate care. The only students who spontaneously note how little time nurses spend on these "core" areas are those with prior experience as nursing assistants. Moreover, most students do not assert that care is a part of professional nursing autonomy. There is, therefore, a contradiction between a theoretical definition of nursing centred on care and another view in which care is not central nor is it claimed as an important aspect of a nurse's daily activity. These contradictions about care appear in students who have nearly finished their education and who soon will be the new generation of professionals. 


\section{DISCUSSION}

Nursing theory clearly places care at the centre of the discipline. Yet these students who are nearing the end of their formal education voice contradictory views of care. These results suggest that they have a troubling perception of nursing. For these students care defines the nursing profession and differentiates it from others. However, and paradoxically, they accept without question that nurses spend most of their time on technical tasks and that they delegate care to nursing assistants.

It is fitting that students talk about help in their attempt to characterise nurses or define the profession. Caring means helping people with their physical or inter-relational needs, such as the need for company or understanding, and the provision of this care is the responsibility of the nurse (Quintero \& Gómez 2010). The desire to help is a basic element of the profession and one of the key reasons for choosing and carrying out nursing studies (Ramió 2005, Buitrago-Echeverri 2008, De Cooman et al. 2008, Price 2009, McLaughlin 2010, Jirwe \& Rudman 2012, Halperin 2014, Wu et al. 2015). The help that students refer to as a characteristic of the nursing profession also coincides with theoreticians' characterisation of the profession (Marriner \& Alligood 2007). Caring, as some authors note (Alberdi \& Cuxart 2005), is an act of reciprocity in which the assisted person receives a service and nurses develop their potential through an established relationship. This notion of reciprocity identified in the literature appears when students say that helping others is a way of helping themselves.

At the same time, the theoretical definition of care that the participants voice, in which greater importance is given to psychological aspects and in which more biological aspects are relegated to a second level, coincides with studies such as that of Maben, Latter and Clark (2007). In this study carried out with final-year student nurses during the last week of their prequalification courses in UK universities, students also spoke about care in a 
holistic way that emphasised its psychological aspect. This form of care centred on the person's needs and not around the nurses' activities or organisational concerns. However, these results differ from those of Khademian (2008), which showed that students considered technical care to be more important than affective care, such as fostering trust or comfort. Despite this apparent disagreement, Maben (2007) argues that what the students display is an idealised understanding of care that is taught in their courses and that reflects curricular goals. In this sense, it is important to recall that students receive not only theoretical training but also practical training in the healthcare setting. Clinical practice allows students to observe professional reality and compare it with what they have absorbed in other learning environments and through theoretical means (Arreciado \& Isla 2015). This idealised view of care (Maben et al. 2007) and of nursing coincides with arguments by other authors such as Price (2009) and Ramió (2005): students, through their observation of professional nursing practice during contact with the healthcare world before entering nursing school, construct an idealised image of nursing based on the idea of helping and closeness. This view, which has influenced their choice of studies, undergoes change during the socialisation process.

In addition, these results show the idealisation of care and of nursing, which is brought to light by the students who have experience as nursing assistants. Their practical education in a healthcare setting allows students to see that the idea of care differs from the reality of care. As well, this difference between the novice's typical idealisation and reality appears in work by Cohen (1988), who describes the clash that new professionals experience when they graduate and face the reality of healthcare. New nurses discover that greater importance is awarded to mechanical tasks than to patient care, resulting in large numbers of nurses leaving the profession after one year of employment. On the other hand, students with experience as nursing assistants noted that direct patient care is not always performed by the nurse. Moreover, despite the fact that students considered care to be the core of the profession, in 
general they were not surprised that nurses spend most of their time on other activities. The only students who spontaneously noted how little time nurses spend on these "core" areas were those with prior experience as nursing assistants. This finding brings to the table an important question. If care is so easily handed over to other professionals, is care truly granted the importance that it appears to have in official definitions? The answer appears to be "no": In official definitions, care is idealised as the primary task of nursing, but it is not emphasised in practice.

In a technologically-oriented healthcare system such as the current one, the value attributed to technology is so high that nurses are overloaded with tasks related to diagnosis. As a result, attention to other needs of the person is compromised (Alberdi \& López 2004, Lleixá et al. 2009). The role of nurses is relegated to tasks that complement medical tasks and therefore, the remainder of nursing care and other professional services are much harder to provide (Alberdi \& Cuxart 2005). As Blackman's (2015) research suggests, as nurses' work intensifies, they have less time to provide care. Moreover, the fact that students aren't surprised by how little time nurses dedicate to care and by how much they dedicate to other tasks could be interpreted as evidence of how little importance they attribute to care (Fajardo \& Germán 2004). This conclusion is reinforced by the fact that only a single student associated the management of care with nursing autonomy. As we have seen in Khademian's (2008) work, the students considered affective care to be less important than technical care. The students' perceptions of the delegation of care also coincide with other research. Studies of patient views show that patients see nursing assistants as the people who handle direct care and who ensure that patients are comfortable (Quintero \& Gómez 2010). As shown by De la Cuesta (2007) and as expressed by students, the transfer of care duties from nurses to nursing assistants or even friends and family is unquestioned and even taken for granted. This finding is particularly relevant given that these students will replace the current generation of nurses. 
The results described here reveal a problem in the transmission of the definition of nursing to new generations of professionals. Students internalise the message that care is the core of the profession but also the difficulty of its implementation in practice and its delegation to others. Moreover, this transfer doesn't seem problematic, given the little value assigned to care. These messages are likely reflections of the professional reality whose contradictions could be attributed to a variety of factors, including the higher value assigned to technical activities; a hierarchy of knowledge in nursing education in which basic science is more valued than practice; the distance between theoretical and practical education; and the on-going submission of nursing to medicine. All of these possibilities should be taken into account as hypotheses for future research.

\section{Limitations}

The main limitation of this research is the fact that it was not possible to observe and conduct focus groups with the same students. However, the criteria of homogeneity and heterogeneity were taken into account in the formation of each group to ensure typicality and diversity. The findings provide an in-depth study of the phenomenon that may be relevant in similar contexts. Furthermore, they can be used as a baseline in future research on the contradictions surrounding the theory and practice of care.

\section{CONCLUSION}

At the end of their education, these nursing students hold a vision of care that is clearly troublesome. In addition to "textbook" definitions that students use to describe care as the core element of nursing, there is another view in which care is undervalued and unthinkingly delegated to others. These facts reflect a problematic professional reality dissonance between 
what nursing is said to be and what actually occurs in practice. The student observes, participates in and internalises this reality. A strong profession requires clarity and coherence on these matters and in nursing these aspects are lacking.

The contradiction between official nursing theory and nursing practice should be resolved. Given that care defines the profession in nursing theory, the academic and professional culture (understood jointly as the norms and values that inform the teaching and practice of nursing) should promote the internalisation of values that have care as the cornerstone for building a new discourse about professional nursing practice. Practical nursing education and clinical nursing practice should be reoriented to reflect the core value attributed to care in nursing theory. This change requires the development of new curricula as well as the implementation of work spaces in which the centrality of care is clearly reflected.

\section{REFERENCES}

Alberdi R.M. (1992) The professional identity of the nurse. Revista ROL de Enfermería 170, $39-44$

Alberdi R.M. \& Cuxart N. (2005) Cares, nurses and professional development: A reflection on the bases of the professional exercise. Presencia 1(2). Retrieved from http://www.index-f.com/presencia/n2/23articulo.php>.

Alberdi R.M. \& López C. (2004) Nursing role versus European role. The difficult bridge between teaching and health assistance in the new Europe. Revista ROL de Enfermeria 27(10), 712-716.

Arreciado A. \& Isla M.P. (2015) Theory and practice in the construction of professional identity in nursing students: A qualitative study. Nurse Education Today 35(7), 859-863. doi.org/10.1016/j.nedt.2015.03.014.

Barrenetxea M., Cardona A., Barandiaran M., Mijangos J.J. \& Olaskoaga J. (2013) The 
development of professional identity at university: a proposal from the teaching in Business Management. Revista de Docencia Universitaria 11(2), 413-441. Retrieved from http://red-u.net/redu/files/journals/1/articles/450/public/450-2382-1-PB.pdf.

Begum S. \& Slavin H. (2012) Perceptions of caring in nursing education by Pakistani nursing students: An exploratory study. Nurse Education Today 32 (2), 332-336. doi: 10.1016/j.nedt.2011.10.011.

Berenguera A., Fernández MJ., Pons M., Pujol E., Rodríguez D. \& Saura S. (2014) Listen, observe and understand. Reclaiming the narrative in Health Sciences. Contributions of qualitative research. Institut Universitari d'Investigació en Atenció Primària Jordi Gol, Barcelona.

Blackman I., Henderson J., Willis E., Hamilton P., Toffoli L., Verrall C., Abery E. \& Harvey C. (2015) Factors influencing why nursing care is missed. Journal of Clinical Nursing 24(1-2), 47-56. doi: 10.1111/jocn.12688.

Buitrago-Echeverri M.T. (2008) Reasons to study nursing and doubts about the profession. The voices of students. Investigación en Enfermería: Imagen y Desarrollo 10(1), 21-38. Cano-Caballero M.D. (2004) Nursing and gender. Time for thinking in order to change. Index de Enfermería 13(46), 34-39.

Celma M. \& Acuña A. (2009) Influence of the feminitation of their professional development in nursing. Revista de Antropología Experimental 9(9), 119-136.

Cohen H.A. (1988) The nurse's quest for a professional identity. Grijalbo, Barcelona.

Collière M.F. (1991) Towards the recognition of nursing practice. Notas de Enfermería 1(9), $53-66$.

Currie E.J. \& Carr-Hill R.A. (2013) What is a nurse? Is there an international consensus?. International Nursing Review 60(1), 67-74. doi:10.1111/j.1466-7657.2012.00997.x. 
De Andrés J. (2000) Qualitative study analysis. Atención Primaria 25(1), 42-46. doi:10.1016/S0212-6567(00)78463-0.

De Cooman R., De Gieter S., Pepermans R., Du Bois C., Caers R. \& Jegers M. (2008) Freshmen in nursing: jobs motives and work values of a new generation. Journal of Nursing Management 16(1), 56-64. doi: 10.1111/j.1365-2934.2007.00800.x.

De la Cuesta C. (2007) Caring for others: challenges and possibilities. Investigación y Educación en Enfermería 25(1), 106-112.

De la Cuesta C. (1997) Characteristics of qualitative research and its relationship to nursing. Investigación y Educación en Enfermería 15(2), 13-24.

Dimitriadou A., Pizirtzidou E. \& Lavdaniti M. (2013) The concept of socialization in nursing education. International Journal of Caring Sciences 6(3), 314-318.

Domínguez C. (1989) The perception of caring. Revista ROL de Enfermería 127, 25-27.

Erickson F. (1989) Qualitative methods on research of teaching. In Handbook of research on teaching II. Qualitative methods of observation (Wittrok M. ed.), Paidós MEC, Barcelona, pp. 203-247.

Fajardo M.E. \& Germán C. (2004) Influence of genre in the reconnaisance of the visible and invisible nursing cares. Index de Enfermería 13(46), 9-12.

García I. \& Buendía A. (2001) Identity and identification of nurses. Revista Rol de Enfermería 24(7-8), 539-545.

Gómez O.J., Daza L.A. \& Zambrano V.M. (2008) Care perception in nursing students: characterization and impact for the formation and vision of professionals. Avances en Enfermería 26(1), 85-96.

Guba E. (1981) Credibility criteria in naturalistic research. In Teaching: theory and practice (Gimeno J. \& Pérez A. eds.), AKAL, Madrid, pp. 148-165.

Halperin O. \& Mashiach-Eizenberg M. (2014) Becoming a nurse. A study of career choice 
and professional adaptation amog Israeli Jewish and Arab nursing students: A quantitative study. Nurse Education Today 34(10), 1330-1334. doi: 10.1016/j.nedt.2013.10.001.

Henderson V. (2006) The concept of nursing. Journal of Advanced Nursing 53(1), 21-31. doi: 10.1111/j.1365-2648.2006.03660.x.

Henderson V. \& I.C.N. (1971) Basic principles of nursing care. International Council of Nurses, Basel, Ginebra.

International Council of Nurses. Definition of Nursing 2. [online]. I.C.N., Geneve. Available at: http://www.icn.ch/who-we-are/icn-definition-of-nursing/ [accessed 15 December 2015].

Jirwe M. \& Rudman A. (2012) Why choose a career in nursing? Journal of Advanced Nursing 68(7), 1615-1623. doi: 10.1111/j.1365-2648.2012.05991.x.

Khademian Z. \& Vizeshfar F. (2008) Nursing students' perceptions of the importance of caring behaviors. Journal of Advanced Nursing 61(4), 456-462. doi: 10.1111/j.13652648.2007.04509.x.

Kozier B. (2005) Fundamentals of nursing. McGraw-Hill Interamericana, Madrid.

Krueger R.A. (1991) Focus groups: a practical guide for applied research. Pirámide, Madrid.

Labrague L.J., McEnroe-Petitte D.M., Papathanasiou I. V., Edet O.B., Arulappan J. \& Tsaras K. (2015) Nursing students' perceptions of their own caring behaviors: A multicountry study. International Journal of Nursing Knowledge doi: 10.1111/2047-3095.12108.

Lleixá M., Gisbert M., Marqués L., \& Albacar N. (2009) The nursing profession and the competential levels. Revista ROL de Enfermería 32(11), 742-746.

Maben J., Latter S. \& Clark J.M. (2007) The sustainability of ideals, values and the nursing mandate: evidence from a longitudinal qualitative study. Nursing Inquiry 14(2), 99-113. doi: 10.1111/j.1440-1800.2007.00357.x. 
Marriner A. \& Alligood M.R. (2007) Nursing theorists and their work. Elsevier Science, Madrid.

McLaughlin K., Moutray M. \& Moore Ch. (2010) Career motivation in nursing students and the perceived influence of significant others. Journal of Advanced Nursing 66(2), 404412. doi: 10.1111/j.1365-2648.2009.05147.

Morse J.M., Solberg S.M., Neander W.L., Bottorf J.L. \& Johnson J.L. (1990) Concepts of caring and caring as a concept. Advances in Nursing Science 13(1), 1-14.

Morse J.M. (2005) Emerging from the data: The cognitive processes of analysis in qualitative inquiry. In Critical issues in qualitative research methods (Morse J.M. ed.), San Vicente del Raspeig, Universidad de Alicante,pp. 53-76.

Palacios D. (2007) The modern construction of nursing. Cultura de los Cuidados 22, 26-32.

Price S.L. (2009) Becoming a nurse: a meta-study of early professional socialization and career choice in nursing. Journal of Advanced Nursing 65(1), 11-9. doi:10.1111/j.1365-2648.2008.04839.x

Quintero M.T. \& Gómez M. (2010) Nursing care means help. Aquichán 10(1), 8-18.

Ramió A. (2005) Professional attitudes and values. Study of professional nursing practice in Catalonia. (Doctoral Dissertation)Universitat de Barcelona, Barcelona

Ruiz J.I. (2007) Qualitative research methodology. Universidad de Deusto, Bilbao.

Sánchez B. (2002) Identity and empowerment of the nursing profession. Avances en Enfermería 20(1), 22-32.

Sargent A. (2012) Reframing caring as discursive practice: a critical review of conceptual analyses of caring in nursing. Nursing Inquiry 19(2), 134-43. doi: 10.1111/j.14401800.2011.00559.x.

Schensul S.L., Schensul J.J. \& LeCompte M.D. (1999) Essential ethnographic methods : observations, interviews, and questionnaires. Altamira Press, Walnut Creek, London, 
New Delhi.

Shinyashiki G. T., Mendes I. A. C., Trevizan M. A. \& Day R. A. (2006) Professional socialization: students becoming nurses. Revista Latino-Americana de Enfermagem 14(4), 601-607.

Suárez M. (2005) Discussion group:a tool for qualitative research. Laertes, Barcelona.

Taylor S.J. \& Bogdan R. (1992) Introduction to qualitative research methods. The search for meanings. Paidós, Barcelona.

Valles M. (2007) Qualitative methods in social research. Reflection on methodology and professional practice. Síntesis, Madrid.

Wade G.H. (1999) Professional nurse autonomy: concept analysis and application to nursing education. Journal of Advanced Nursing 30(2), 310-318. doi: 10.1046/j.13652648.1999.01083.x.

Wu L.T., Low M.M.J., Tan K.K., Lopez V. \& Liaw S.Y. (2015) Why not nursing? A systematic review of factors influencing career choice among healthcare students. International nursing review 62 (4), 547-562. 